Research Report No. 43/2013

\title{
Jurisprudential Disagreements and Descriptivism
}

Dan Priel

Osgoode Hall Law School of York University, dpriel@osgoode.yorku.ca

Follow this and additional works at: http:/ / digitalcommons.osgoode.yorku.ca/clpe

\section{Recommended Citation}

Priel, Dan, "Jurisprudential Disagreements and Descriptivism" (2013). Comparative Research in Law \& Political Economy. Research Paper No. 43/2013.

http://digitalcommons.osgoode.yorku.ca/clpe/285 


\section{OSGOODE}

OSGOODE HALL LAW SCHOOL

YORK UNIVERSITY

\section{OSGOODE HALL LAW SCHOOL}

Comparative Research in Law \& Political Economy

RESEARCH PAPER SERIES

Research Paper No. 43/2013

\section{Jurisprudential Disagreements and Descriptivism}

Dan Priel

\section{Editors:}

Peer Zumbansen (Osgoode Hall Law School, Toronto, Director Comparative

Research in Law and Political Economy)

John W. Cioffi (University of California at Riverside)

Jonathan Ungaro (Osgoode Hall Law School, Toronto, Production Editor)

Comparative Research in Law \& Political Economy 


\title{
Furisprudential Disagreements and Descriptivism ${ }^{\star}$
}

\author{
Dan Priel $^{\dagger}$
}

\begin{abstract}
Many contemporary legal philosophers argue that general jurisprudence is "descriptive." I challenge this view in this essay by focusing on one familiar aspect of jurisprudence: persistent disagreements among legal philosophers. I argue that this fact is in tension with the claim that jurisprudence is descriptive. I consider several possible reconciliations of jurisprudential disagreements with descriptivism, but I argue that none of them succeeds. I then argue that persistent jurisprudential disagreements are easy to explain from within a normative framework. I conclude by suggesting that legal philosophers abandon descriptivism in favor of a view that more explicitly sees legal philosophy as part of normative political philosophy.
\end{abstract}

From a historical perspective the questions that occupy the center stage of contemporary analytic jurisprudence are something of a newcomer. The philosophy of law has been traditionally understood as a normative enterprise with close relations with moral and political philosophy. This is true of both those theorists now classified as natural lawyers as it is of those now considered early exponents of legal positivism. The twentieth century has seen a radical transformation of this understanding of jurisprudence is about. Following the very influential work of Hans Kelsen and H.L.A. Hart many legal philosophers, especially (but not exclusively) legal positivists, have begun to think that the primary task of jurisprudence is descriptive. According to this view, which I will call "descriptivism," jurisprudence is first a conceptual inquiry concerned with offering an account of the "nature of law," it is general in the sense that it is applicable to all legal systems, and it is morally neutral in that it does not pass judgment on whether law (either in general or any of its particular instantiations) is morally good or bad. Descriptivists do not deny, of course, that it is possible to talk about specific laws and to pass moral judgment on them, but they insist that descriptivism is both possible and that it is a valuable intellectual pursuit. Some further argue that the descriptive inquiry is logically prior to the normative one. Their opponents challenge either one of the two elements that make up descriptivism, insisting that it is impossible to give an account of law that is both general and does not appeal to moral considerations, and they deny the claim that to the extent one can describe law, this inquiry enjoys logical priority to

* This essay is in some respects incomplete. It used to have a companion essay that addressed the question of what it is that legal philosophers purportedly "describe." It had the additional virtue of answering all possible challenges to this essay; it was, alas, kept (without backup) on a computer that got stolen. I hope it will be written again one day.

${ }^{\dagger}$ Associate Professor, Osgoode Hall Law School. I gratefully acknowledge the comments and suggestions from Imer Flores, Mike Giudice, François Tanguay-Renaud, Bas van der Vossen, and Ekow Yankah on earlier versions. I also thank audiences in the National Autonomous University of Mexico and in the IVR conference in Belo Horizonte, Brazil, for their comments and questions on earlier versions of this essay. 
normative questions. Though descriptivism has not been universally accepted, it remains, I think, the more popular view among contemporary legal philosophers. ${ }^{1}$ In this essay I challenge descriptivism by arguing that it is inconsistent with the nature of jurisprudential debates.

I

There are ongoing debates among legal philosophers that purport to be about the nature of law. By this I do not refer to debates among lawyers about the "grounds" of law in a given legal system, but to the debates among legal philosophers themselves about the correct account of the nature of law. ${ }^{2}$ At their narrowest these theories purport to be "descriptive" in that they seek to offer an explanation or explication of what law while leaving open the question of whether (or when) law is a good or a bad thing. If true, a descriptive theory of law could be accepted both by the committed legalist and the philosophical anarchist. But these theories are also descriptive in another, though related, sense. They are said to be descriptive also in that they purport to tell us what law is without appeal to normative considerations, or at least without appeal to practical (moral or political) normative considerations. For convenience I will call the normative considerations descriptivists allow "non-moral considerations." The aim of such an inquiry is to identify what law is, to be able to provide a good classificatory scheme for distinguishing those things that are law from those things that are not. The restriction of the inquiry to non-moral considerations is there to identify the object of inquiry in an objective fashion, not unlike scientists' identification of the nature of physical substances. And it is exactly for this reason that the findings are descriptive also in the first sense: just as the correct identification of the physical structure of say, water, does not pass judgment on whether water is a good or a bad thing, so does the correct identification of the nature of law remain silent on whether having law is good or bad.

There are differences among the various defenses of descriptivism. One difference in particular is of significance for my argument: some descriptivists

${ }^{1}$ Among other endorsements of descriptivism see H.L.A. Hart, The Concept of Law, 2nd ed. (Oxford: Clarendon Press 1994) 239-44; Scott J. Shapiro, Legality (Cambridge, Mass.: Harvard University Press, 2011) 2-4; Larry Alexander \& Emily Sherwin, The Rule of Rules: Morality, Rules, and the Dilemmas of Law (Durham: Duke University Press, 2001) 204-09; John Gardner, Law as a Leap of Faith (Oxford: Oxford University Press, 2012) 23-24; Andrei Marmor, Philosophy of Law (Princeton: Princeton University Press 2011) ch. 5; Jules L. Coleman, "Beyond the Separability Thesis: Moral Semantics and the Methodology of Jurisprudence," 27 Oxford Fournal of Legal Studies 581, 597-608 (2007). Another defense of "descriptive jurisprudence" is found in Brian Leiter, Naturalizing furisprudence: Essays on American Legal Realism and on Naturalism in Legal Philosophy (Oxford: Oxford University Press, 2007) 164-75, but there are some significant differences between Letier's views and those of other descriptivists, so my argument here is not directed at his views.

${ }^{2}$ The main strategy of the leading anti-descriptivist, Ronald Dworkin, has been to argue that it is impossible to distinguish clearly between these two types of question. If this were true, then jurisprudential debates (and disagreements) would be unquestionably morally evaluative. Dworkin's claim has been vigorously denied by descriptivists. My argument does not depend on this claim and to narrow the scope of potential disagreement with descriptivists I assume they are correct on this point. 
contend that they describe "the concept of law," while others claim to explain "the nature of law," or "law itself." The distinction is often elided-Hart, to take one prominent example, freely moved between talking about "the concept of law" and the "nature of law"-but it will prove important. By the "concept" of law I refer to something like people's beliefs about law, roughly along the sense psychologists use the term concept; by "nature," I refer to the practice itself. The argument I develop below is concerned with those theorists who purport to explicate the nature of law. ${ }^{3}$ It is this understanding of descriptive jurisprudence that is difficult to reconcile with the fact of persistent disagreement.

\section{II}

My argument, in brief, is that the existence and persistence of disagreements over the nature of law gives us reason to doubt the claim that jurisprudential disagreements are in fact descriptive in the sense identified above. Now, unquestionably, that disagreements exist over a descriptive question is not immediately a cause for concern, nor is it a reason to doubt the descriptiveness of the question. I may disagree with you on what I take to be an unquestionably descriptive question, say, the height of the Empire State Building. The straightforward explanation for our disagreement is, typically, at least one of us is mistaken. It is also typical of such disagreements, however, that they are not persistent; all we need to do is find a source we accept as authoritative on the matter, consult it and find who of us (if any) is right.

The mere fact of persistence also does not automatically warrant the conclusion that the disagreements are not descriptive; but it does call for an explanation. As I see it, there are four potential explanations for persistent disagreements that are consistent with descriptivism. I call the first epistemic deficiency. In cases of epistemic deficiency there is insufficient data on a matter under consideration resulting in gaps that leave room for several competing descriptive accounts. Currently, for example, there is disagreement among evolutionary theorists on what provides a better account of the process of natural selection, whether it is through slow, relatively constant, changes (a view called "gradualism"), or whether it is in spurts of relatively quick change followed by period of relative stasis (this is known as the "punctuated equilibria" view). This is, at its core, an empirical question, but it is one for which much of the relevant evidence is not available. If better data on Earth's natural history were available, scientists would be able to answer which of these two (if any) is correct. While the debate in this example is still open, the history of science provides numerous

${ }^{3}$ For claims to explicating the nature of law (law itself) rather than the concept of law see Gardner, Law as a Leap of Faith, p. 276 n. 14; Michael S. Moore, Educating Oneself in Public: Critical Essays in furisprudence (Oxford: Oxford University Press, 2000) 311; Andrei Marmor, "Farewell to Conceptual Analysis (in Jurisprudence)," in Wil Waluchow \& Stefan Schiaraffa (eds), Philosophical Foundations of the Nature of Law (Oxford: Oxford University Press, 2013) 209, 216-17. For a very close argument see Joseph Raz, Between Authority and Interpretation: On the Theory of Law and Practical Reason (Oxford: Oxford University Press, 2009) 18-24. 
examples of scientific disputes that were resolved once more evidence became available.

The second possible explanation for persistent descriptive disagreements is the complexity of the object. The idea here is quite straightforward: The complexity of the object of inquiry makes it difficult to provide an accurate description of it, hence the potential for persistent disagreements. Applied to the domain of jurisprudence, disagreements over what law is exist and persist because the subject-matter to be explained-law-is very complex and disagreements result from theorists' endless struggle to get a better grasp of legal phenomena.

A third possible source of persistent descriptive disagreements may be, explicitly or implicitly, the result of disagreement over values. I assume that even the most committed moral realist will admit that there are persistent disagreements over moral questions and that there is currently no agreed method of resolving them. As a result, evaluative disagreements are difficult to resolve and are typically persistent. Call these "moral evaluative disagreements." On some metaethical views moral evaluative disagreements are the result of epistemic deficiency on moral matters, but for the moment I will assume this is not the case. For those who believe that the source of disagreement on moral matters is epistemic, moral evaluative disagreements are therefore a special case of what I called epistemic deficiency. (I say something about this possibility below.)

The final possible source of persistent disagreement consistent with descriptivism is what I call apparent disagreement. Apparent disagreements exist when, despite appearances and disputants' own beliefs, they do not in fact talk about the same thing. For example, if two people disagree over whether Dworkin thinks people have a right to pornography, their disagreement may be due to the fact that one is talking about Ronald while the other about Andrea. Though facetious, this example highlights an important point about apparent disagreements, namely that though definitely possible, apparent disagreements are less likely to persist as usually their nature can be discovered fairly quickly. Indeed, those cases in which disagreements of this type persist are likely to be cases of epistemic deficiency that leads disputants to mistakenly treat two different things as though they were one (or as two different tokens of a single type). As such, the only real cases of this source of disagreement are typically going to be, once again, a special case of the first source of persistent disagreement identified above. Nevertheless, because this case calls for some independent consideration, I will consider apparent disagreements separately below.

It is time to advance my argument against descriptivism. In a nutshell, it is that descriptivism is a true and significant research program for jurisprudence only if the source of disagreement among legal philosophers is epistemic deficiency or complexity; but neither is a plausible explanation of jurisprudential disagreements. Hence, jurisprudential descriptivism is either false or pointless. Let me now try and substantiate this argument. 
III

I start with the explanation that seems most obviously inconsistent with descriptivism, namely that jurisprudential disagreements persist because, at bottom, they are disagreements over moral evaluative questions. The one great virtue of this possibility is that it provides an easy answer to the puzzle of persistent jurisprudential disagreements; on the other hand, this answer seems inconsistent, in a fairly obvious manner, with descriptivism. This can be fairly easily seen if we think of Dworkin's challenge to legal positivism. In many of Dworkin's writings he focused on the fact of disagreement within the law (i.e., not the disagreements I am concerned with here) as an embarrassment to positivist theories of law, and for which Dworkin's view of law as a domain of moral decision-making offered a ready answer. Moving this argument to the level of jurisprudential discussion does not, at first sight, make any difference. That seems to have been Dworkin's own view, as in his later writings he relied on something like this argument in support of the view that legal philosophy is evaluative. ${ }^{4}$ If we accept that the reason why jurisprudential disagreements persist is because they are moral, does this not immediately show that descriptivism is false?

One way of trying to overcome this challenge is to adopt the view that descriptivism requires only describing evaluative judgments, not making a moral argument or taking a stand on an evaluative question. Such an argument has been made for the sake of explaining how jurisprudence can remain descriptive in the context of considering evaluative judgments within the law. As Hart put it, "[d]escription may still be a description, even when what is described is an evaluation." But whatever are the merits of this view in the context of legal philosophers' describing the attitudes of those who take part in legal practice, ${ }^{6}$ this argument cannot be used when evaluative premises are, ex hypothesi, the source of the disagreement among legal theorists. In such a case if one can describe such evaluative attitudes in a morally neutral manner, then we would not expect to see disagreement. If disagreements persist when describing a moral attitude, we are once again facing the problem of explaining persistent disagreements. Indeed, an admission that such disagreements are possible may be a reason for doubting the claim that it is possible to describe a normative attitude neutrally.

Another possibility might be to argue that the supposed contrast between evaluative and descriptive disagreements is misleading, because evaluative disagreements may be descriptive. To say of a sentence that it is evaluative, on this view, is to say that it relates to questions of value, i.e. it is to say something about the reference of the sentence. To say of a sentence that it is descriptive, on the other hand, is to say something about its nature, to say, roughly, that it is about a matter of fact. On this view, it is possible for a sentence to be evaluative

\footnotetext{
${ }^{4}$ Ronald Dworkin, fustice in Robes (Cambridge, Mass.: Harvard University Press 2006) ch. 6.

${ }^{5}$ Hart, Concept of Law, p. 244.

${ }^{6}$ For some doubts see Danny Priel, "Evaluating Descriptive Jurisprudence," 52 American Fournal of Furisprudence 139, 148-50 (2007).
} 
(referring to value) and descriptive (factual) at the same time if we believe that there are facts "in the world" on matters of value. ${ }^{7}$

Would accepting this possibility salvage descriptive jurisprudence? As a historical matter, "descriptive jurisprudence" is associated with legal positivism, and the latter has been attractive to some legal theorists, most famously H.L.A. Hart, who were skeptical of claims of the descriptiveness of ethics, and whom I suspect may have been attracted to descriptive jurisprudence exactly because it was grounded on the firmer factual ground of social practice than on that of morality. The point is, however, of interest beyond intellectual history. Descriptive jurisprudence was premised on the idea that it is possible to give an account of legal practice that is not grounded in morality, that jurisprudential disputes were about the "classificatory" question of what counted as law. The possibility considered here concedes that jurisprudential debates are, at least in part, moral or political debates in disguise, but then tries to salvage descriptivism by appealing to a controversial metaethical theory. Even if this theory is accepted, it is doubtful whether it leaves more than the shell of descriptivism. Descriptivism is based on the view that law is a social practice and as such explicable as a matter of fact. On the reinterpretation under consideration, it turns out that this is false. To accept this explanation for the persistence of jurisprudential debates is to admit what has always been understood (by proponents and challengers of descriptivism alike) to be the antithesis of descriptivism, namely that jurisprudential debates really are moral or political disputes in disguise. What does not change is that the disagreement is persistent and its persistence is due to the fact that questions of value are impossible to resolve. To learn from a metaethical theory that the debate is nevertheless descriptive because questions of value are factual is small consolation indeed, if we cannot in any way ascertain them. Put somewhat differently, the motivation for jurisprudential descriptivism has been the belief that one need not engage in evaluation in jurisprudential inquiry. That motivation does not change when we discover that evaluative statements are factual and therefore, in the sense used in this section, "descriptive."

IV

I turn to consider the possibility that jurisprudential disagreements are apparent disagreements. This may seem a surprising suggestion, for if true, that would imply that many jurisprudential debates are in fact not genuine debates, that much time and effort has been spent on debates in which disputants are in fact arguing past each other. Another reason to doubt this explanation has much to

${ }^{7}$ See Dan Priel, "Description and Evaluation in Jurisprudence," 29 Law and Philosophy 633, 641-44 (2010). The questions of value are factual is related to the view that questions of value of objective, but the link is complex. At least some moral objectivists, such as Dworkin, have insisted that fact and value comprise of two separate domains. See Dworkin, fustice in Robes, pp. 76-78. Consequently, for Dworkin questions of value were inherently contested and (in the sense used in the text) non-descriptive. This is consistent with his "right answer thesis," because of the idiosyncratic meaning Dworkin gave this idea. See ibid., pp. 41-43. 
do with jurisprudential disagreement is that, as mentioned earlier, we expect such disagreements to be resolved rather quickly, once the parties realize they do not really disagree. To be persistent on this account, it has to be the case that jurisprudential disagreements are apparent but those who engage in them do not (and perhaps cannot) learn this fact.

Despite its apparent oddity, the suggestion that jurisprudential disagreements are apparent should be fairly familiar. A common strategy for explaining away several longstanding jurisprudential disagreements has been to argue that they are the result of apparent disagreement. It has been suggested, for instance, that natural lawyers are concerned with the case of moral or just law whereas legal positivists seek to explain its less exalted instantiations; or to pick another wellknown example, it has been suggested that much of the disagreement between legal positivists and Dworkin may simply reflect failure to notice that positivists offer a theory of law and Dworkin a theory of adjudication. ${ }^{8}$ The first thing to note about these suggestions is that they do not correspond to how natural lawyers or Dworkin understand their own work: These critics of legal positivism clearly considered their views a challenge to positivist views and when faced with such conciliatory suggestions they flatly rejected them. ${ }^{9}$ But the issue is not merely "biographical." After all, it is possible that these theorists have misunderstood their work or its implications. The heart of the matter is that explanations of different aspects of a single phenomenon are, if they are both true, complementary; indeed, necessarily so. Explaining jurisprudential disagreement as the result of apparent disagreement of this sort requires us to accept that virtually all legal theorists made not only the error of failing to notice their accounts dealt with different matters, but also the further error of finding conflicts among themselves when none existed. While not impossible, the suggestion that such global misunderstanding is at the heart of all debates among legal philosophers seems rather implausible. What is even more curious is that such misunderstandings would persist (on what is said to be a descriptive matter) even after the error has been pointed out. If that were the source of all jurisprudential disagreements, one would wish to see an explanation as to why so many intelligent legal theorists continue to get their own views so badly confused.

While I do not find these particular examples very compelling, I nevertheless believe that apparent disagreements count for at least some persistent disagreement in jurisprudence. The first important source of apparent disagreement in jurisprudence is that legal philosophers have different views on what counts as law, what belongs to the object to be explained. This is because different legal theorists do not approach their theoretical inquiries with a clean slate; rather, they enter into the debate with different assumptions on the sort of things that belong to the object of inquiry. Some legal theorists, to make this point less abstract, are pretheoretical "natural lawyers" and therefore do not

\footnotetext{
${ }^{8}$ For examples of these strategies: With regard to natural law see Gardner, Law as a Leap of Faith, pp. 51-53; with regard to Dworkin see ibid., p. 184.

${ }^{9}$ See John Finnis, "Law and What I Truly Should Decide," American fournal of Furisprudence, 48 (2003) 107, 127-29; Dworkin, fustice in Robes, pp. 30-33, 162-68, 184-85.
} 
include unjust legislative prescriptions as part of the object to be explained while others are pretheoretical "legal positivists," who do. As a result of their different starting points, they end up with conflicting descriptive theories, but because the disagreement exists at a level that cannot be touched by their descriptive theories, the disagreements persist. Apart from the problem of circularity (what justifies those pretheoretical starting points?), to the extent that jurisprudential disagreements are the result of such pretheoretical disagreements, it looks like no descriptive theory can convince those not already committed to the starting point it is based on, hence the persistence of (some) jurisprudential disagreements.

That is a serious problem for descriptivism, and it is the result of the fact that unlike in the case of scientific description, there is neither an agreed-upon "sample" on which different theorists can theorize, nor an agreed-upon methodology that can be used to determine that sample without biasing the conclusion in favor of one approach. As a result, it is always possible to dismiss any potential counterexample to one's theory as not really a case of law, something that each side can do since what counts as law is not fixed in advance. Even the choice of methodology for fixing the object of inquiry is itself suspect and potentially question-begging for, once again, favoring one conclusion over others. To give a concrete example: what role, if any, should prevailing attitudes among people play in answering the question of the nature of law? We can imagine at least three different answers: according to the first, prevailing attitudes should play no role whatsoever, for the philosophical inquiry into the nature of law is entirely separate from the sociological one; according to a second, we should conduct surveys to examine people's attitudes on the matter; and according to a third, we should be interested in people's attitudes on the matter, but there is no need for surveys because the philosopher can rely on himself and his own experiences as a guide for this question. (There are, of course, other possibilities and variations on these three basic types.) Further complicating the matter is the fact that these positions can relate to two levels of inquiry, that of setting the object of inquiry and that of providing the explanatory (or descriptive) theory. There are, therefore, at least six methodological positions, and different legal theorists have expressed different views on the choice among them. And yet, until we have been given a reason to favor one answer over others, the prospects for descriptive jurisprudence that does not beg all important questions look grim. Crucially for our purposes, the question of the choice between these possibilities cannot itself be considered "descriptive."

To avoid talking past each other legal philosophers will have to agree on a "descriptive" (in this context: normatively neutral) way of deciding what counts as law prior to beginning their theorizing. It is not clear how they can do that, when the question what counts as law is exactly what the point of contention among them. What is likely to happen is that each side will favor the methodology that fits its preconceptions. In fact, I believe this is exactly what has happened: much of the debate between legal positivists and anti-positivists these days revolves implicitly around the question whether the question of the nature of law is a question about explaining a social practice, or is part of a broader inquiry 
that involves addressing questions about nature and human nature. ${ }^{10}$ If one adopts the former approach, the conclusion that law is a "social construction," nowadays taken by many legal positivists to be the core of their view, follows almost inevitably. If one adopts the latter approach, that conclusion appears, at the very least, incomplete.

This problem can be generalized: a central reason why jurisprudential disagreements persist is because of underlying methodological issues: the point of jurisprudence and philosophy, the nature of explanation in general and of social phenomena in particular. These are wide-ranging issues, but if they have one thing in common is that none of them can be called "descriptive." (I return to this issue below.)

Another possible source of apparent disagreement in jurisprudence is mistaken generalizations. The problem here is that in spite of legal philosophers' claims to generality, they are in fact often erroneously trying to generate an account of the "nature" of law in general from the few legal systems they happen to be familiar with, despite the fact that different legal systems-contrary to descriptivists' assumptions-do not share a single nature. On this view, disagreement may be the result of different generalizations based on different phenomena. Though this possibility is often dismissed out of hand by descriptivists, I think something like it explains some jurisprudential disagreements. There are fundamental differences between different legal systems that reflect different understandings of what law is (differences that ultimately arise from different normative views on the role of law, as well as differences in the social, political, and technological environment), and that some of the disagreements among legal philosophers, as well as their persistence, are the result of failure to take such differences into account. ${ }^{11}$

Those who reject this claim may raise two valid challenges: First, to claim that different legal systems belong to different kinds must presuppose some way of individuating legal systems, something that the arguments about circularity mentioned earlier preclude. Even if this problem is overcome, a second challenge arises, namely, why would such disagreements persist when the information on the locality of explanation is readily available? The brief answer to the first challenge is that it is possible to individuate legal systems to different "types" on evaluative grounds, i.e. exactly in a way that is not available to the descriptivist. My response to the second challenge is the "sociological" observation that most legal philosophers, and especially so these days, do not seem particularly interested in actual law beyond their (often limited) knowledge of their own legal system, nor do they take particular interest in those disciplines (comparative law, legal anthropology, and legal history) that provide the relevant information for assessing such a claim.

${ }^{10}$ See Dan Priel, "Toward Classical Legal Positivism" (unpublished manuscript), available at http://ssrn.com/abstract=1886517.

${ }^{11}$ See Dan Priel, "Is There One Right Answer to the Question of the Nature of Law?" in Philosophical Foundations of the Nature of Law, 322. For examples of dismissal of such a claim see Shapiro, Legality, pp. 16-17; Moore, Educating Oneself in Public, pp. 80-81. 
I do not want to spend too much time on this issue or press it too strongly, because the relevance of this observation is tangential for the matter at hand. If I am wrong about it, that simply means that one potential source for explaining the source of jurisprudential disagreement is unavailable. If it is true, descriptivism may remain a viable possibility on a more local level, once we distinguish between the different phenomena put together under the same label, "law." But even if we accept this possibility, the difficulties for descriptivism are far from over. First, deciding whether two different phenomena are two tokens of the same type is not something that can be done by mere observation and description, as different phenomena in the world do not come with labels attached to them. Therefore, adopting this as an explanation for jurisprudential disagreement will require justifying which of the differences between various specimens of law are differences between tokens of the same type and which are separate types. This means that the problems identified at the level of general jurisprudence cannot be avoided by attempting to defend descriptivism on a smaller scale. Distinguishing between different types within the category "law" will require an underlying theory, which brings back the problem of circularity mentioned above.

Even if we manage to overcome this problem, it will still require a major change in descriptivism. Recall that one of the two central elements of descriptivism is that it offers a general description of law. This is no small thing. Describing the important elements of particular legal systems is exactly the sort of thing descriptivists themselves claim not to be doing, the sort of task they consider as the appropriate domain of empirical social scientists. ${ }^{12}$ Therefore, narrowing down the aims of descriptive jurisprudence in this way will raise doubts on its very point and will presumably call for some fundamental changes in the methods legal philosophers use. In particular, one would expect their work to be much more grounded in empirical facts on particular legal systems than it currently is.

\section{$\mathrm{V}$}

I turn now to epistemic deficiency and complexity as possible reconciliations of persistent jurisprudential disagreements with descriptivism. Let me start with the first possibility, because it is a more evidently implausible explanation for jurisprudential disagreement. As far as I know, there are no constitutions to be unearthed, statutes whose content awaits interpretation, or any other missing facts that if found would bring any open jurisprudential question to an end. To be sure, we do not know everything that can be known about all historical forms of law, just as we do not know many aspects of life in ancient times. But that is besides my point, because there is no suggestion that certain currently open jurisprudential disputes on the nature of law would be resolved if only we had some information about ancient legal systems we currently lack. That is not just my own view. Unlike cases of scientific epistemic deficiency when scientists can tell what evidence will resolve an open scientific dispute (and when possible they

${ }^{12}$ See Joseph Raz, The Authority of Law: Essays in Law and Morality, 2nd ed. (Oxford: Oxford University Press, 2009) 44, 104-05; Shapiro, Legality, pp. 406-07 n. 16; Gardner, Law as a Leap of Faith, pp. 177, 193-94. 
often go on to construct and conduct experiments in an attempt to gather it), I know of no suggestion from any jurisprudential descriptivist that any presently open jurisprudential disagreement will be resolved if only certain facts become known.

It is this crucial difference between jurisprudential and scientific disagreements that explains why Scott Shapiro's recent attempt to explain jurisprudential disagreements is inapt. According to Shapiro, "[j]ust as two detectives can disagree about which suspect committed the crime, two philosophers can disagree about what makes an entity the thing that it is." ${ }^{\prime 3}$ In his scenario disagreement is possible because it is the result of epistemic deficiency. Even if the available evidence renders several possible scenarios equally plausible, we can conceive of additional evidence that would have shown which of the detectives (if any) is right. In his scenario, for example, a security camera installed at the crime scene could have resolved the detectives' disagreements. There is simply nothing comparable in jurisprudence.

Complexity is a more serious possibility. Here, if you wish, the source of the disagreement is not the insufficiency of data but the insufficiency of legal theorists' cognitive capacities. Obviously, this is a possibility that can never be ruled out, but I think it provides little assistance to defenders of descriptivism. To see why, we need to look a bit more closely at the potential sources of complexity and their implications for jurisprudential disagreement. In general we can distinguish between complexity of the explanandum and complexity of the explanans. I begin with the former.

Though superficially appealing, the complexity of the explanandum actually fits jurisprudential disagreements rather poorly. Legal phenomena are indeed multifaceted and varied; nonetheless, their complexity should not be exaggerated. Law is not quantum mechanics (about which Richard Feynman is reputed to have said: "if you think you understand quantum mechanics you don't understand quantum mechanics"). When one examines jurisprudential disagreements, they are not normally accusations of ignoring some facts or of leaving out some aspect of a complex phenomenon, but are rather the result of challenging a competing explanation of the same, typically not exceptionally complex, set of facts. A related difficulty with this explanation lies not with what we see in jurisprudential debates, but with what we do not. If it had really been the complexity of the explained phenomena that accounted for jurisprudential disagreement we would have expected to see the sort of progress we do see in the paradigm of "descriptive" inquiries, science, where complex theories are built up from an accumulation of answers to small-scale and typically less controversial questions. There is, however, no such accumulation of accepted answers in jurisprudence. I cannot think of a single small-scale problem that has been solved to (virtually) everyone's satisfaction. In fact, there is not even agreement on wrong answers. Among prominent legal philosophers today some believe coercion is essential to law, others do not; some believe that the gunman situation writ large

\footnotetext{
${ }^{13}$ Shapiro, Legality, p. 18.
} 
can under certain situations be a legal system, while others deny this; some believe that morality is necessarily connected to law, others firmly deny this. The list goes on and on. These disagreements are hard to square with the suggestion that the source of such disagreements is due to the complexity of law.

There is a different potential source of legal complexity that may be of greater explanatory power, but unfortunately for descriptivists, if it is true, it undermines descriptivism in a different way. One reason why law may be complex is that it was the product of the workings of many people in different times and places, holding very different and often conflicting views on law, society, morals and politics. Their different views have not just been exogenous evaluations of legal phenomena; rather, these beliefs influenced actions within the law and thereby helped shape what law is. This resulted in a practice within which one finds, say, "positivistic" aspects alongside "non-positivistic" ones, because those who give shape to legal phenomena (legislators, judges, lawyers, lay people) have reshaped legal practice on the basis of their conflicting beliefs. Unlike the complexity in the practical aspects of law, which legal philosophers tend to ignore as irrelevant, this diversity of views touches on the very issues they are concerned to illuminate. The different attitudes of those involved in the law lead to a social practice that is constantly being pulled in different directions. Legal philosophers typically ignore this diversity of views, treating, say, Cicero's claims about the nature of law as external observations about the nature of law (which they can then assess as true or false), and not the statements of a legal insider whose beliefs also contributed to the constitution of what law is.

This complexity provides a straightforward explanation for some jurisprudential disagreements-different descriptivists have their own views about law and they (naturally) highlight in their accounts those features that align with these views and neglect those that do not-but in doing so it also provides what may be the greatest challenge to descriptivism. For if the possibility just outlined is true, conflicting jurisprudential descriptivists are all wrong for ignoring this complexity and offering overly simplified, incomplete, and for that reason erroneous, accounts of law. In short, if law is complex in this sense, then the overly neat and organized accounts legal philosophers give us are not faithful descriptions of the nature of law, but are explanations simplified and sanitized to such a degree that the result cannot plausibly be called a "description" of their purported object.

The only way to avoid this conclusion is to argue that beyond all the differences among legal practitioners there is a core that all agree on and that it is this core of legal practice that legal philosophers can and should describe. There are, however, at least three problems with this suggestion. First, this claim needs to be shown rather assumed; second, it is not easy to both maintain this claim and the one that remaining disagreements among legal philosophers are about the description of this supposedly uncontroversial core; and finally, this core, even if it exists, is likely to be so thin that it will not capture anything that could be plausibly called the "nature" of law, which is what descriptivists purport to be after. 
What about the complexity of the explanans? There are considerable difficulties with this possibility as well. Legal philosophers typically leave out from their discussions much of what makes law complex. According to descriptivists the philosophical question of the nature of law is understood as the search for law's necessary features or its existence conditions. Consequently, much of the diversity (and hence complexity) of real-world legal phenomena is off bounds as far as most legal philosophers are concerned. In fact, to the extent that the complexity of legal phenomena still remains a problem that leads to persistent jurisprudential disagreements, it casts doubt on the appropriateness of philosophical method as a means for dealing with the task of a descriptive account of law. Philosophy is not the only (and typically not the primary) method for describing social phenomena (as opposed to the question of the explaining the ontological status of social phenomena, of what makes them possible). If descriptive jurisprudence fails so spectacularly at providing determinate and agreed-upon answers to the question of describing the essence of a familiar social practice, this gives us reason to doubt whether it is the right tool for the task. In other words, claiming that jurisprudence is descriptive and explaining jurisprudential disagreements as a result of the complexity of law, when coupled with the failure of this enterprise to generate uncontroversial descriptions of even the most basic aspects of law, will tend to suggest that the problem lies in the method used to describe the phenomenon: specifically, the inadequacy of the fact-thin methods of legal philosophers in addressing and describing the factual complexity of the social phenomena they are investigating.

\section{VI}

The following table summarizes the different explanations considered in this essay for explaining jurisprudential disagreements and the reason why each of them undermines descriptivism:

\begin{tabular}{|l|l|}
\hline \multicolumn{1}{|c|}{ Explanation of the disagreement } & \multicolumn{1}{c|}{ Problem for descriptivism } \\
\hline Evaluative moral disagreement & Descriptivism is straightforwardly false. \\
\hline Evaluative epistemic disagreements & $\begin{array}{l}\text { Debates in jurisprudence are pointless } \\
\text { so long as theorists do not find the right } \\
\text { way of explaining law. }\end{array}$ \\
\hline Apparent disagreement & $\begin{array}{l}\text { Implausible as an explanation of } \\
\text { disagreement; but if true disagreement } \\
\text { is pointless and trying to resolve the } \\
\text { disagreement undermines the } \\
\text { motivation for analytic jurisprudence. }\end{array}$ \\
\hline Epistemic deficiency & $\begin{array}{l}\text { Unlikely explanation of jurisprudential } \\
\text { disagreements. }\end{array}$ \\
\hline Complexity of legal phenomena & $\begin{array}{l}\text { Does not fit most jurisprudential } \\
\text { disagreements; and if true undermines } \\
\text { philosophy as a method for getting to } \\
\text { the truth. }\end{array}$ \\
\hline
\end{tabular}


If the arguments just summarized are along the right lines, we have reason to doubt that the branch of jurisprudence that purports to be descriptive is indeed so, because descriptive debates only manifest persistence under certain conditions, none of which pertains to jurisprudential debates.

I consider now several possible objections to my argument. The first, one that I treat briefly, is that even though each explanation considered above in isolation cannot explain why jurisprudence is descriptive, some combination of them can. Or it might be contended that I failed to consider an argument for explaining the persistence of jurisprudential disagreement that will satisfy committed descriptivists. Both challenges are, of course, possible. Without more, all I can say is that these challenges are empty without further details. In any case, even if ultimately unsuccessful, the argument of this essay should prove helpful in making sense of the terrain of descriptive jurisprudence and for a more fruitful discussion of its merits.

The second possible objection, one that I encountered in one form or another from several readers, is that my arguments must be false, because if true, they bring down with them not just descriptive jurisprudence but the whole of philosophy. After all, if there is one thing that has characterized philosophy throughout all its history is the intractability of its questions and the persistence of its debates. Phrased in more positive terms, it may be argued that there is something inherently intractable about philosophical debates, and that my arguments miss this feature of philosophical debates by treating them as though they were empirical. The first thing to say in response is that it is (usually) no answer to a crime to say that others are guilty of it as well; and labeling a debate "philosophical" does not relieve it of normative standards relevant to other inquiries. It bears asking why philosophical debates are persistent, why some ageold questions of philosophy are still with us. It is also notable that those that do not, have usually been answered by other disciplines. If all this means that a branch of philosophy, or even all of it, cannot be salvaged, so be it. But, in any case, I do not actually think that all of philosophy similarly affected by my arguments. Few philosophers these days, as far as I know, call their work "descriptive." Even if we expand this category to mean "conceptual," then conceptual analysis has met with hard times, from philosophers perhaps more than anyone else. It has its defenders too, but to argue that all philosophical reflection is a form of conceptual analysis (which is what this challenge amounts to) is an unlikely claim. Whatever may be the faults in those branches of philosophy that do not purport to be descriptive, the arguments presented in this essay do not affect them.

More specifically, when considered more closely, it is at least arguable that some of the rejected explanations for the persistence of jurisprudential debates are available for explaining the persistence of other philosophical debates. Some debates in philosophy probably persist because of epistemic deficiency (some questions in the philosophy of mind are likely examples, as are some aspects in the debate over free will). More importantly, the arguments presented here do not affect all branches of normative philosophy. If, for instance, general 
jurisprudential explanations were modeled on something like reflective equilibrium, the argument presented here would have left it largely unscathed. (That is not to say that the method of reflective equilibrium has not had its critics, only that those criticisms are unrelated to the ones raised here against descriptivism.) But to think of jurisprudence on the reflective equilibrium model means thinking of it as a normative inquiry. True, reflective equilibrium starts with prevailing understandings of our practices and checks them against our intuitions, but it is a normative endeavor that seeks to justify and improve our practices. Further, the method of reflective equilibrium is justified for its ability to offer reinterpretations of familiar concepts that are normatively attractive, thereby providing a framework for improving human institutions. This is very different from descriptive jurisprudence.

A different objection is that I have missed my target, because in fact even descriptivists concede the role of evaluation in jurisprudential inquiry: what they reject is that those values are moral or political. ${ }^{14}$ Real jurisprudential descriptivists, then, can accept that a main source of jurisprudential disagreement is evaluative, but deny that it is moral evaluation. Call this view "weak descriptivism." 15

For reasons I explained in some detail elsewhere, I believe weak descriptivism is an unstable and indefensible position, ${ }^{16}$ but we can largely ignore these arguments here. We can assume that weak descriptivism is sound. In one recently popular version of weak descriptivism, jurisprudential theory requires making judgments of importance. ${ }^{17}$ Though I have not encountered this specific argument from defenders of this view, one might try to explain the persistence of jurisprudential disagreement on disagreements on what aspects of legal phenomena are important.

This suggestion may seem promising at first, but it suffers from several significant difficulties. It is worth pointing out first it simply does not correspond to jurisprudential discourse. Pick any of the most prominent works in jurisprudence of the last few decades: arguments in it are not typically that other legal theorists give too much or too little weight to certain aspects of law; it is that competing views are wrong. This is hard to reconcile with the claim that evaluative disagreements in jurisprudence are all based on different judgments of

${ }^{14}$ Joseph Raz, Ethics in the Public Domain: Essays on the Morality of Law and Politics, rev. ed. (Oxford: Clarendon Press, 1995) 237; Julie Dickson, Evaluation and Legal Theory (Oxford: Hart, 2001).

${ }^{15}$ Some may have qualms about attaching the label "descriptivism" to this view given that it accepts the role of some values in jurisprudential theorising. The label does not matter much, of course, but in calling this view descriptive I follow the view of some self-styled descriptivists who allow for this form of evaluation in their account. See e.g., Marmor, Philosophy of Law, p. 124; Leiter, Naturalizing Furisprudence, pp. 174-75; Alexander \& Sherin, Rule of Rules, p. 207; H.L.A. Hart, "Comment," in Ruth Gavison (ed.), Issues in Contemporary Legal Philosophy: The Influence of H.L.A. Hart (Oxford: Clarendon Press, 1987) 35, 39.

${ }^{16}$ See Priel, "Description and Evaluation in Jurisprudence"; Dan Priel, "Evaluating Descriptive Jurisprudence," 52 American Fournal of Furisprudence 139 (2007).

${ }^{17}$ Dickson, Evaluation, pp. 51-69; cf. Jules L. Coleman, The Practice of Principle: In Defence of a Pragmatist Approach to Legal Theory (Oxford: Oxford University Press, 2001) 196-97. 
importance. A second difficulty with this suggestion is that different emphases should not lead to conflicts. It is normally not difficult to recognize that two accounts that differ simply in how much they highlight different aspects of a single phenomenon. Therefore, for this to count as the source of jurisprudential disagreements what is needed is the further assumption that these different judgments of importance have been globally mistaken for something else. As I see it, the most likely reason why this might be so is if different judgments of importance is if they affect legal practice, i.e. if judging certain features of law to be more important than others leads to a somewhat different legal practice. But this explanation is fundamentally at odds with descriptivism, for it suggests that legal philosophers do not stand outside legal practice merely observing and describing it, but rather (inadvertently or not) they take a stand-a normative stand-between different possible forms that legal practice takes. That would show that judgments of importance are in fact implicit judgments as to the relative merits of different forms of legal practice.

Assume, however, that I am wrong about all this too, i.e. that the source of jurisprudential disagreement is evaluative and exclusively confined to disagreement over assessments of the important features of law. Accepting this as the source of persistent jurisprudential disagreements will prove a pyrrhic victory for the descriptivist, for if this is the case, that will render jurisprudential disputes beyond argument. As far as I know there is no way of adjudicating between judgments of importance, for they are subjective: if I think that certain features of law that I find important vindicate "natural law theory" and you think that other features that you find important lead to "legal positivism," it is hard to see the point of us debating our views, because each can only be assessed relative to those judgments of importance, and those judgments themselves are beyond dispute. Descriptivists must implicitly accept this point, because if they did not, they would probably address this question and suggest a way of identifying correct and incorrect judgments of importance in order to resolve jurisprudential disputes in this way. I know of no attempt to do that. ${ }^{18}$

Perhaps, however, this focus on judgments of importance is insufficiently narrow. Perhaps jurisprudential disagreements are the result of competing epistemic values. This is a more plausible version of weak descriptivism, but again I find it unlikely that it is only epistemic values that explain jurisprudential disagreements. They definitely do not seem that way. Those who propose this as the source of persistent jurisprudential disagreements need to show how evaluative disagreements about the nature of a normative institution such as law can steer clear of moral or political considerations. I would further wish to see an

${ }^{18}$ I raise in a note a related problem. Charles Taylor has argued that judgments of "import" are embedded in a particular worldview. See Charles Taylor, "Self-Interpreting Animals," in Human Agency and Language: Philosophical Papers 1 (Cambridge: Cambridge University Press, 1985) 45. As the title of his essay indicates, this argument is particularly pressing for those who claim (and this includes many descriptivists) that jurisprudence is a hermeneutical endeavor concerned with "selfunderstanding." If Taylor is right, the possibility of "objective" (in this context: cross-culturallysimilar or even interpersonally-similar) judgments of importance, and hence of explanation of social phenomena that depend on such judgments, looks rather suspect. 
argument demonstrating how virtually all jurisprudential disagreements are the result of disagreement over epistemic values. It is worth highlighting in this context that disagreements of this sort are likely to result from different views about the proper way of explaining human action, and that such disagreements are themselves not easily disentangled from moral and political questions. (As an example consider debates about the relationship between rationality and morality.)

However, for the sake of argument, as before, I am willing to grant the assumption that moral evaluative considerations do not form any part of the evaluative considerations that affect persistent jurisprudential disagreements. Once again, an immediate implication of this view is that most debates among legal philosophers are misguided, although this time for a somewhat different reason than before: it follows from this version of weak descriptivism that disagreements among legal philosophers that purport to be about the nature of law are actually competing views about explanation, either in general or of human action. While I happen to think that some jurisprudential disagreements are in fact the result of different views on the nature of (good) explanation, it is hard to see how a defender of jurisprudential descriptivism will find solace in this view. Accepting it implies that to the extent that jurisprudential disagreements are the result of epistemic evaluative disagreements, legal philosophers should turn away from the debates they have been engaged in and turn to the matters that are really behind their disagreements, i.e. the appropriate method for explaining human behavior, action, and institutions.

The second potential challenge to my argument is that the source of evaluative disagreement is epistemic deficiency on matters of value. This is the possibility mentioned briefly at the beginning of the essay, according to which evaluative disagreements are a special case of epistemic deficiency. I do not think this is a very popular view, but it has its adherents; Ronald Dworkin, for example, may have been one of them. As I understand him, Dworkin believes legal and moral disagreements exist because we lack the powers of his imaginary judge Hercules, and correspondingly, that all such disagreements would have disappeared had we been omniscient like him. Would adopting this view make a difference to the question at hand? Technically, the answer is clearly "No," because jurisprudential disagreements will still be evaluative, and more specifically, morally evaluative. More importantly, to try and explain the prevalence of jurisprudential disagreements within a descriptivist framework by appealing to this consideration implies that descriptivists should dedicate all their efforts to non-jurisprudential questions. On this view jurisprudential debates are ethical or metaethical debates masquerading as debates about the nature of law and there is little hope for one side convincing the other of the truth of its views until we find the truth regarding certain ethical questions. Put somewhat differently, accepting this view implies that jurisprudential debates should look 
much more like Dworkin's work in jurisprudence, work that has been, decidedly and consciously, non-descriptivist. ${ }^{19}$

VII

So far I have presented reasons to doubt the claim that jurisprudence is descriptive and considered several possible counterarguments. I wish to conclude with a positive explanation of the debates that make up what is said to be descriptive, or conceptual, jurisprudence in a way that will make sense of their persistence.

Calling jurisprudence descriptive suggests that there exists a well-defined object that exists before the inquiry. That is indeed the assumption, usually implicit, one finds in the work of descriptivists. Raz, for instance, has stated that it is a mistake to think that "legal philosophy creates the concept of law" when "in fact it merely explains the concept that exists independently of it." 20 We have seen, however, that because there is no clearly-defined object, descriptive jurisprudence suffers from a fatal flaw of circularity, which can be avoided when we abandon this assumption. If we accept that law is a human creation, then what belongs in that category is itself determined by human attitudes. Though this is almost a truism among contemporary legal philosophers, especially legal positivists, the full implications of this idea have not been considered. The most significant one for present purposes is that since (for the most part) humans have no need for a clear-cut classification of law and non-law, there simply is no answer within the object itself to many of the questions that have been at the heart of descriptive jurisprudence, because there are no (consistent) human attitudes about them. This implies that there is no answer to many of the "descriptive" questions at the heart of contemporary conceptual jurisprudenceQuestions like: Is law necessarily coercive? Can moral norms be incorporated into the law? Are sanctions necessary for law? - because humans have not had any need to come up with answers to them. To give just one example, the claim that the concept of law does not necessarily involve sanctions has been challenged using thought experiments involving non-human societies. But since humans, whose attitudes constitute the object on which legal philosophers supposedly apply their conceptual analysis skills, have not troubled themselves with the question of law in non-human societies (the law of human societies giving them enough to worry about), it is a mistake to draw any inference from whatever it is one imagines is the right answer to these thought experiments, to any inquiry into the nature of law.

The only way out of this is to try to describe not simply a human practice, but an idealization of it. Now, here there are two ways of identifying that ideal. One is

19 Incidentally, such an explanation for jurisprudential disagreements will also require abandoning the claim made by some prominent descriptivists that legal positivism is neutral between different metaethical views. See H.L.A. Hart, Essays in Furisprudence and Philosophy (Oxford: Oxford University Press, 1983) 78; Joseph Raz, "Legal Principles and the Limits of Law" in Marshall Cohen (ed.), Ronald Dworkin and Contemporary Furisprudence (London: Duckworth, 1984) $73,85$.

${ }^{20}$ Joseph Raz, Between Authority and Interpretation, p. 85. 
an attempt to strip from the practice what the theorist considers its underlying ideal. That, I trust it is clear, involves exactly the normative inquiry that descriptivists claim is not part of their inquiry. The difficulty is that the practice underdetermines its ideal and that consequently there is an infinite number of possible idealizations of it. The other possibility is that the ideal of law is itself an attitude the theorist tries to identify. On this view real-life law is a pale image of an abstract idea of law that the humans whose attitudes have constituted legal practice have created them with a certain ideal in mind. In that case, we might think of a "descriptive," even "sociological" inquiry of this ideal. I take it that such ideals have indeed occupied lawyers and philosophers. The problem here, however, is not of a lack of an object to describe, but of a glut. History shows they have had many such ideals, and the choice among them inevitably takes us beyond description.

All different ways of understanding jurisprudential practice thus show it to involve some kind of interpretation of the practice, i.e. the attempt to look at the practice and identify what is central to it and why this is so. This explanation seems plausible on its own: the most "descriptive" jurisprudence involves the sifting and organizing of certain facts as relevant, essential, important, illuminating and so on, from an infinite number of facts. This process is not descriptive, for making those judgments requires taking a certain normative perspective. It also provides a ready and simple explanation for our puzzle of persistent jurisprudential disagreement. Indeed, it does so while also explaining why such disagreements are often presented as though they are disagreement over a "descriptive" question. This is so, because such accounts appear to give us an account of what the practice "is," not what it should be. These competing interpretations are thus normative, grounded in whatever normative considerations the theorist more-or-less explicitly recognizes as relevant for this inquiry. The persistence of jurisprudential disagreement is made possible by the fact that there is indeterminacy at all levels of this inquiry: of what belongs to the object of inquiry, of the standards by which to assess it, the content of those normative standards, the weighting of such different standards, and so on.

I thus reach, relying on a somewhat different argument, a conclusion that is quite similar to the one reached by Ronald Dworkin. But Dworkin has made the further claim that jurisprudence is political in the sense that this shows that jurisprudence is part of political philosophy. Is this extra step warranted? If we agree that different "descriptive" theories of law are in fact different interpretations of legal practice, the question remains as to the relevant standard. In some loose and not very illuminating way we can talk of here of "importance" as the relevant standard, but if we try and consider what is important about law, it is safe to say, I think, without prejudicing my answer in favor of any view, that law is related to concepts like authority, morality, coercion, and legitimacy. All these are political concepts. Thus, any interpretation of what law is (what is important, illuminating, central, and so on about it) will require explaining how these concepts (or at least some of them) relate to law and to each other. Even if there is a descriptive component to such an inquiry, it is probably a minor part of 
it, and cannot be the whole of it. Thus, even if not all interpretation of social practices is political, the interpretation of law is.

VIII

Even if all this is convincing, one may wonder why any of this matters. My real concern is broader than the seemingly technical question of whether descriptivism is defensible or not. My hope is that this essay will persuade readers of the need to turn away from descriptivism, because I believe descriptivism has led legal philosophers to spend an inordinate amount of time and energy on the wrong questions, and, perhaps worse, try to answer them, in ways that did not contribute to better understanding law. Given what I have just said, this claim requires some explanation. After all, if, as I have just contended, jurisprudential debates really are something different from what those engaged in them claim them to be, then the problem may not be with the debates themselves, only with their characterization. But the characterization of debates as conceptual does have very deleterious effects on jurisprudence. They involve many scholars engaged in questions for which the characterization offered here shows there is no "descriptive" or "conceptual" answer; they deepen the separation of jurisprudence from political philosophy and encourage the view that in answering questions in jurisprudence one should, as much as possible, stay clear of normative debates. As a result the descriptive bias in contemporary jurisprudence has led to the wrong answers to fundamental questions in jurisprudence and to the isolation of jurisprudence from legal practice, from the rest of legal academia, and even from the rest of contemporary philosophy.

Part of the dominance of conceptual jurisprudence has involved the creation of an invented history, in which philosophers of past centuries, especially those considered founders of legal positivism, have had their philosophy of law made to fit descriptivist strictures leading to characterizations of their thought that bear only a tenuous relationship with their actual ideas. This is true of Hobbes, of Bentham, even to some extent of John Austin. This essay does not attempt to spell out what an alternative view of jurisprudence should look like, but these examples (to which one can add many more) suffice to establish one point: that the range of possibilities and views one could find in legal philosophy is as wide as what one finds within political philosophy. Under this characterization of jurisprudence the puzzle of persistent jurisprudential disagreements will no longer be a mystery, or at least not a greater mystery than the existence of persistent disagreements among political philosophers. More importantly, thus understood, the point of engaging in these persistent debates will become much easier to understand. On this view jurisprudential arguments will be understood not as attempts to describe law, but rather as attempts to persuade others of the superiority of a particular way of understanding and organizing legal phenomena based on a broader view on how life in a political community should be lived and the role law should play in it. Some works will be "interpretive" in that they will try to work by offering a politically-informed reading of existing practices; other works will be purely "prescriptive" or "normative" as they will try to articulate a 
characterization of justified legal practices independently of such practices. None should be "descriptive." 